\title{
Responsabilidad extracontractual de la administración pública en el código civil y en normas de derecho administrativo ${ }^{1}$
}

\author{
Soto Hernández, María Eugenia*
}

\section{Resumen}

El hecho de considerar a la responsabilidad extracontractual de la Administración Pública como una institución de carácter iuspublicista, no imposibilita la aplicación de manera supletoria de las normas del Código Civil, sobre todo en el régimen de responsabilidad por actuaciones ilícitas de la actividad administrativa. El régimen jurídico de la responsabilidad extracontractual de la Administración Pública tiene su base y sustento en la Constitución de la República Bolivariana de Venezuela y además existen normas de carácter legal que coadyuvan a fundamentarlo. Se estudia en primer lugar, las normas relativas a la responsabilidad en el Código Civil y en segundo lugar, las normas de derecho administrativo concernientes a la responsabilidad extracontractual de la Administración Pública. Se establece su aplicabilidad de acuerdo a los dos regímenes de responsabilidad extracontractual de la Administración Pública, por falta y sin falta. El diseño del trabajo de investigación se apoya en la estrategia de investigación descriptiva. El método que se sigue es de carácter analítico. Se concluye que en el sistema de responsabilidad extracontractual de la Administración Pública las normas del Código Civil son de carácter supletorio y sus supuestos de aplicabilidad no serán considerados intromisiones, sino, que por el contrario, se trata de un derecho común aplicable, en algunos casos, a las categorías de derecho administrativo.

Palabras clave: Responsabilidad extracontractual, Administración Pública, Régimen legal, Venezuela.

Recibido: 00-09-11 . Aceptado: 01-10-22

Abogada. Especialista y Magíster en Derecho Administrativo. Doctora en Derecho. Investigadora y docente adscrita al Instituto de Estudios Políticos y Derecho Público (IEPDP) de la Facultad de Ciencias Jurídicas y Políticas de La Universidad del Zulia (LUZ), Venezuela. Investigadora acreditada al Programa de Promoción al Investigador (PPI) del CONICIT. Telefax: 0261-7596676. E-mail: mesotoh@cantv.net.

1 Esta investigación forma parte del Proyecto de Investigación "La Noción del Daño Antijurídico en la Responsabilidad Extracontractual de la Administración Pública”, financiado por el Consejo de Desarrollo Científico y Humanístico (CONDES) en el período 1999-2000. 


\section{Extra-Contractual Responsibility in the Public Administration of the Civil Code and the Norms of Administrative Law}

\section{Abstract}

The fact of considering extra-contractual responsibility in Public Administration as an institution of a iuspublicista character, does not deny the supplemental application of Civil Code norms, especially in a regime of responsibility for illicit acts committed by administrative activity. The judicial regime for contractual responsibility in Public Administration is based on the Constitution of the Bolivarian Republic of Venezuela and there are norms of a legal character that help to establish its base. Norms related to Responsibility in the Civil Code are first studied, and then the norms of administrative law that refer to extra-contractual responsibility in Public Administration. The applicability is established in relation to both regimes of extra-contractual responsibility in Public Administration, with cause and without. The research design was descriptive. The method followed was analytical. The conclusion is that in relation to the system of extra-contractual responsibility in Public Administration, Civil Code norms are not suppletory and their supposed applicability is not considered an intromission, but on the contrary, they are common laws applicable in some cases to categories of administrative law.

Key words: Extra-contractual responsibility, public administration, legal regime, Venezuela.

\section{Introducción}

El objetivo general consiste en evaluar la aplicación del Código Civil y la de algunas normas de derecho administrativo en la institución de la responsabilidad extracontractual de la Administración Pública, bajo un enfoque analítico de las referencias doctrinarias y avances jurisprudenciales venezolanos que al respecto se han emitido.

El diseño del trabajo de investigación se apoya en la estrategia de investigación descriptiva. El método que se sigue es de carácter analítico. Las fuentes para la recolección de la información se refieren a los siguientes tres ámbitos de profundidad: A) Ámbito jurídico. Los instrumentos normativos pertinentes son los siguientes: Código Civil (CC),
Ley Orgánica de Procedimientos Administrativos (LOPA), Ley Orgánica de la Corte Suprema de Justicia (LOCSJ), Decreto con rango y fuerza de Ley Orgánica de la Administración Central (DLOAC), Ley de Expropiación por Causa de Utilidad Pública o Social (LECUPS), Ley Orgánica de Ordenación Urbanística (LOOU), Ley Orgánica para la Ordenación del Territorio (LOOT) y la Ley de Tránsito Terrestre (LTT). B) Ámbito doctrinario: Comprende la lectura y análisis exhaustivo de la doctrina venezolana y extranjera acerca del régimen legal de la responsabilidad extracontractual de la Administración Pública. C) Ámbito jurisprudencial: se consulta la jurisprudencia venezolana en original, en algunos casos, y en otros, los repertorios mensuales de jurisprudencia. 


\section{Normas relativas a la responsabilidad en el Código Civil}

Es innegable que la teoría de la responsabilidad tiene su origen en el derecho privado. La actitud de un sujeto que reviste formas de culpabilidad, como el dolo y la culpa, y que como consecuencia de ello le causa un daño a otro es un postulado de la teoría civilista. La responsabilidad extracontractual es una institución formada por postulados, teorías, principios que tiene su origen en el derecho civil y se expande su aplicación a las demás ramas de la ciencia del derecho, en este caso el derecho administrativo. Esta institución resarcitoria de daños se basa en un conjunto de reglas de derecho, ya sea de derecho privado o de derecho público.

En primer lugar, se analiza el término responsabilidad. La responsabilidad puede ser contractual o extracontractual, a pesar de la posición de la doctrina que no admite su separación. En la primera de ellas existe un convenio, una convención entre los sujetos de derecho, denominada contrato, una de las partes no cumple la obligación contractual derivada del acto convencional. La segunda de ellas se refiere a la obligación que debe existir en cada sujeto de derecho para observar y cumplir conductas que han sido predeterminadas y dispuestas por el legislador. Ambos aspectos de la figura de la responsabilidad son aplicables al campo del derecho civil y al campo del derecho administrativo.

En este sentido la responsabilidad que compete dilucidar sería la relativa a la extracontractual, aquella que surge del incumplimiento de normas de derecho, sean primarias o de primer orden, -constitucionales-, secundarias o de segundo orden,- legales-, y terciarias o de tercer orden, - reglamentos, decretos y demás instrumentos jurídicos.

En segundo lugar, se presenta el estudio de la siguiente afirmación: Cuando se refieren a la responsabilidad civil ordinaria, se aplican las normas del Código Civil, normas de derecho privado. Si se trata de la responsabilidad extracontractual de la Administración Pública, se aplican normas de derecho público, entre éstas, la Constitución y las normas administrativas correspondientes. ¿Es del todo cierta esta afirmación?

El trabajo no pretende analizar las normas del Código Civil y calificarlos de fundamentos normativos de la responsabilidad extracontractual de la Administración Pública, sólo que debido a la incesante utilización de estas normas por el jurisconsulto venezolano, resulta necesario identificarlas y esbozar algunos comentarios al respecto, y enfatizar en la responsabilidad civil ordinaria y el daño moral.

\subsection{Responsabilidad civil ordinaria}

De acuerdo a la corriente privatista la responsabilidad civil ordinaria se refiere a dos figuras o instituciones: el hecho ilícito y la responsabilidad especial por guarda de cosas.

\subsubsection{El hecho ilícito}

Está previsto en el art. 1185 del Código Civil: "El que con intención, o por negligencia, o por imprudencia, ha causado 
un daño a otro está obligado a repararlo. Debe igualmente reparación quien haya causado un daño a otro, excediendo, en el ejercicio de su derecho, los límites fijados por la buena fe o por el objeto en vista del cual le ha sido conferido ese derecho" (Congreso Nacional, 1982). La jurisprudencia y la doctrina civil es conteste en considerar al incumplimiento ilícito como uno de los elementos constitutivos de la responsabilidad civil por hecho ilícito. Cuestión que se diferencia de la responsabilidad extracontractual de la Administración Pública, por derivar ésta tanto de actuaciones lícitas como ilícitas. Ello se desprende del contenido del art. 140 de la Constitución de la República Bolivariana de Venezuela (CRBV) que describe la responsabilidad de la Administración Pública como un derecho. "El Estado responderá patrimonialmente por los daños que sufran los o las particulares en cualquiera de sus bienes y derechos, siempre que la lesión sea imputable al funcionamiento de la Administración Pública" (Asamblea Nacional Constituyente, 1999; Corte Suprema de Justicia/Sala de Casación Civil, CSJ/SCC, 1991, citado por Pierre Tapia, 1991:79).

El hecho ilícito es una de las fuentes extracontractuales de las obligaciones, si se quiere, la figura por excelencia de la responsabilidad extracontractual en el campo ius-privatista. El adjetivo ilícito plantea dos puntos de vista: el primero representado en un hacer o en un no hacer, actuación positiva o negativa por parte del autor del daño, y el segundo figurado en dos situaciones jurídicas distintas: la del que abusa de su derecho y la del que procede sin ningún derecho. "Para incu- rrir en abuso de derecho es necesario que en su ejercicio se hayan excedido los límites fijados por la buena fe y en el caso que se examina, considera la Sala que por el solo hecho de que se acuse o denuncie a una persona que luego es declarada inocente, no puede estimarse que se incurrió en exceso, que se traspasaron los límites fijados por la buena fe..." (CSJ/SCC, 1996, citado por Pierre Tapia, 1996:139s.).

En este mismo orden de ideas, la jurisprudencia venezolana ha establecido los elementos y los supuestos del hecho ilícito a saber: “...Se señalan, por tanto, como elementos del hecho ilícito: 1) la actuación u omisión; 2) la ilicitud de la acción u omisión; 3) el daño; 4) la relación de causalidad; y 5) la culpa." (Corte Suprema de Justicia/Sala Político Administrativa CSJ/SPA, 1996, citado por Pierre Tapia, 1996:141).

\subsubsection{Responsabilidad especial por guarda de cosas}

La responsabilidad especial por guarda de cosas, ha sido normativa invocada por los demandantes y la Corte Suprema de Justicia, hoy Tribunal Supremo de Justicia, en Sala Políticoadministrativa, ha resuelto casos de responsabilidad extracontractual de la Administración Pública amparada en esta normativa. Estipula el art. 1193, primer párrafo "Toda persona es responsable del daño causado por las cosas que tiene bajo su guarda, a menos que pruebe que el daño ha sido ocasionado por falta de la víctima, por el hecho de un tercero, o por caso fortuito o por fuerza mayor" (Congreso Nacional, 
1982). En dictamen de la Procuraduría General de la República de fecha $11 / 7 / 1983$ se señala que la responsabilidad por guarda de cosas se fundamenta en una presunción de culpa in vigilando, de carácter absoluto, por lo tanto no le está permitido al guardián probar que ha cumplido con sus deberes de vigilancia y control sólo se exonerará al demostrar la causa extraña no imputable (Fundación Procuraduría General de la República, 1983:345s.).

La jurisprudencia venezolana cataloga a esta disposición como la consagración de la responsabilidad objetiva en el caso Nemecio Cabeza vs. Compañía Anónima de Administración y Fomento Eléctrico (CADAFE), al estipular que sólo en presencia de estas causas no imputables a la conducta desplegada por el guardián de la cosa, se podrá exonerar de responsabilidad. Así mismo, se plantea que la responsabilidad se tornará más evidente cuando se trata de cosas que representan un peligro objetivo, de las cuales el guardián obtiene un beneficio. Por ejemplo, el caso de la existencia de un depósito de explosivos en una empresa del ramo. "Si se trata de una cosa peligrosa, dentro de las cuales podemos incluir sin dudas a la electricidad, y aún más la de alta tensión, de la cual el guardián saca un provecho, resulta obvio que debe asumir totalmente las consecuencias que deriven del riesgo que crea" (CSJ/SPA, 1994b).

De igual forma en el caso Nelson Wilfredo Molina Montoya contra CADAFE se estipula que el artículo 1193 consagra una presunción de culpa juris et de jure, que no admite prueba en contrario. En la cual se podrá entablar una nueva relación de causalidad entre la causa extraña no imputable y el daño producido (CSJ/SPA, 1989, citado por Pierre Tapia, 1989:35).

\subsection{Daño moral}

El art. 1196 del CC dispone "La obligación de reparación se extiende a todo daño material o moral causado por el acto ilícito.

El Juez puede, especialmente, acordar una indemnización a la víctima en caso de lesión corporal, de atentado a su honor, a su reputación, o a los de su familia, a su libertad personal, como también en el caso de violación de su domicilio o de un secreto concerniente a la parte lesionada.

El Juez puede igualmente conceder una indemnización a los parientes, afines, o cónyuge, como reparación del dolor sufrido en caso de muerte de la víctima" (Congreso Nacional, 1982).

En este orden de ideas, lo discutible, en este caso, será si todo este conjunto de normas podrá aplicarse, o no, a la responsabilidad extracontractual de la Administración Pública. Lo cierto es que sí se han venido aplicando por vía jurisprudencial este sistema privatista de reparación de daños causados por la Administración Pública.

La responsabilidad extracontractual de la Administración Pública, en principio se nutrió de la rama privatista del derecho civil antes de alcanzar su autonomía y especificidad propia. Es innegable la influencia civilista que tienen las decisiones en materia de responsabilidad de la Administración Pública en Venezuela, la mayoría de los casos son resueltos bajo la aplicación de esta normativa. Pero, en realidad, ¿Qué papel juegan las 
normas del Código Civil en esta materia?, ¿Sirven para sustentar todo el sistema de responsabilidad de la Administración Pública, incluyendo tanto el régimen de responsabilidad por falta y sin falta?

\subsection{Papel que juega las normas del Código Civil en la Responsabilidad de la Administración Pública}

Las normas del Código Civil sólo tendrán un valor determinante en el campo de la responsabilidad por funcionamiento anormal o por falta, cuando es relevante la conducta del funcionario que causó el daño y poder determinar así qué tipo de falta ha cometido, es decir, si se trata de una actuación culposa, dolosa, ilegal. En el campo de la responsabilidad sin falta, la figura de la responsabilidad civil ordinaria no tiene ningún sentido y no goza de aplicación, acá no se estudia la conducta del funcionario, el estudio de la misma carece de relevancia, sólo es importante la producción del daño y que el mismo sea imputable a la Administración Pública.

Sin embargo, la figura del daño moral no afecta de ninguna manera la responsabilidad que se aplique, trátese de responsabilidad civil ordinaria o responsabilidad de la Administración Pública. Esta es una norma, cuya aplicación no desna turaliza la esencia de la institución de la responsabilidad de la Administración Púr blica, muy por el contrario, la enriquece.

Cabe entonces destacar que las normas constitucionales, legales y sublegales atinentes a la responsabilidad extracontractual de la Administración Pública serán aplicables de forma principal a todo el sistema, sea por falta o sin falta, las normas del Código Civil cumplen un papel secundario. Sólo que en el campo de la responsabilidad por falta o funcionamiento anormal, el Código Civil puede aplicarse de forma principal, cuando se toma en cuenta la falta que ha cometido el funcionario y se evalúa la conducta del funcionario o agente que ha causado el daño y por ende, ha lesionado algún derecho de los particulares.

Ahora bien, si se ostenta de un bloque de normas constitucionales abiertas, perfectas, de fuerza dominante se hace innecesaria la referencia a las normas civilistas que se prevén en materia de responsabilidad extracontractual civil a la hora de pretender indemnizaciones por daños provenientes de la actuación lícita de la Administración Pública. La invocación de las mismas resulta improcedente y si se remonta a los orígenes de la autonomía de la responsabilidad de la Administración Pública frente al derecho civil se puede sustentar esta tesis en la sentencia del 8 de Febrero de 1873 del Tribunal de Conflictos en Francia, caso Agnes Blanco, donde se determina su separación de los conceptos civilistas.

Con respecto a la Constitución de 1961 (CV), en Venezuela la Procuraduría General de la República, en un dictamen del 19/10/1993, ha reconocido que el régimen de la responsabilidad del Estado está contenido en el art. 47 y además ha establecido que dentro del mismo cuerpo legal, - debió decir constitucional -, se encuentran otras disposiciones (arts. 3, $206,232)$ que, conjuntamente con el art. 47 , conforman la base fundamental del sistema venezolano de responsabilidad 
estatal. Sin embargo, este órgano consultivo ha considerado que el régimen constitucional de responsabilidad estatal no cuenta con la normativa necesaria que lo implemente o desarrolle, por lo que se ha establecido de forma unánime, tanto en el ámbito doctrinal como jurisprudencial, que en su defecto se aplicarán los casos de responsabilidad civil extracontractual, los preceptos de derecho común relativos al hecho ilícito.

De manera que se establece en la doctrina administrativa los presupuestos necesarios para hacer efectiva la responsabilidad extracontractual del Estado: 1. Invocar el art. 47 de la CV como punto de partida. Se debe entonces demostrar los siguientes requisitos acumulativos: la existencia de un daño, que el daño fue ocasionado por una autoridad legítima y que esta autoridad al producir el daño actuaba dentro de su función pública. 2. Una vez cumplidos los extremos del art. 47 se acogerán las disposiciones del Código Civil referentes al hecho ilícito. Asimismo ha sostenido de manera imprescindible que tanto los particulares al fundamentar su acción, como los órganos judiciales al decidir, aleguen y prueben los primeros, y comprueben, los segundos, la existencia no sólo de los elementos constitutivos del hecho ilícito común, es decir, la culpa, el daño y la relación de causalidad, sino que de manera procedente $\mathrm{e}$ indefectible deben establecer que se han llenado las exigencias del art. 47 de la Constitución, pues en esta norma es donde se encuentra la base fundamental para hacer efectiva la responsabilidad patrimonial del Estado por las actuaciones de sus autoridades legítimas en ejercicio de sus funciones públicas (Fun- dación Procuraduría General de la República, 1993:130s.).

De igual forma, en el dictamen de fecha 10/03/1987 el órgano consultivo de la Administración Pública ratifica que los principios expuestos en el texto constitucional no han sido desarrollados por la ley, en virtud de lo cual la responsabilidad de la República se ha sustentado en el art. 1191 del CC (Fundación Procuraduría General de la República, 1987:152).

Estas posiciones de la doctrina administrativa de la Procuraduría General de la República es parcialmente objetable. Si bien es cierto que el régimen de responsabilidad del Estado está contemplado en las normas constitucionales y en especial referencia al art. 47, ¿por qué se debe dar una vuelta atrás, hacia las normas civilistas cuando la autonomía de la responsabilidad de la Administración Pública está ampliamente demostrada? Cuando se habla de responsabilidad extracontractual sin falta, no se debería mencionar la figura del hecho ilícito que es una figura netamente civilista y que en nada se corresponde con la actuación lícita de la Administración.

Por otra parte, en la jurisprudencia venezolana se ha invocado constantemente las normas del Código Civil para interponer y fundamentar los libelos de demanda en casos de responsabilidad extracontractual del Estado. Se presentan de esta manera algunas de estas decisiones:

En el caso Ramón Gallardo vs. INOS el actor fundamenta su demanda en normas del Código Civil: arts. 1185, 1193 y 1194 (CSJ/SPA, 1994d).

En el caso Juan Simón Mijares Camejo vs. INOS en el capítulo del objeto de 
la demanda se indica que: "fundamenta el apoderado actor la demanda en lo dispuesto en los artículos 1 y siguientes de la Ley de Expropiación por causa de Utilidad Pública o social, y del artículo 1185 del Código Civil" (CSJ/SPA, 1994e). La normativa legal presentada por la figura de la expropiación era realmente suficiente para sustentar los alegatos esbozados.

A su vez, en el caso Laboratorios Sanalo, la jurisprudencia fundamentó su decisión en las normas constitucionales vigentes para esa fecha y determinó que el hecho ilícito acaecido debía ser indemnizado conforme a los artículos 47 y 206 de la Constitución (CSJ/SPA, 1993).

Por el contrario, en el fallo Asociación Educacional Avila vs. República de Venezuela, el cual es referido a un funcionamiento anormal del servicio, donde la Administración ocupó una propiedad privada con la finalidad de restablecer el orden público, pero sin cumplir las formalidades legales, se puede justificar la invocación de normas civiles hasta cierto punto: "En consecuencia, la ocupación realizada por las Fuerzas Armadas de Cooperación configura un hecho ilícito, generador de daños reparables por la República de Venezuela, a tenor del artículo 1.185 del Código Civil, y así se declara" (CSJ/SPA, 1994c). Si bien es cierto que las normas constitucionales y las normas de derecho administrativo son las aplicables, de forma principal, sólo en el caso del funcionamiento anormal de la Administración Pública, comprobada como fuere la falta, procede la aplicación de la corriente privatista.

En el caso José Rafael Marin y Navol Bautista Martínez Díaz vs. CADAFE, dos particulares demandaron a ésta para que convenga en pagarles por concepto de daño moral la cantidad indemnizatoria que fije al Juez, conforme lo establece el art. 1196 del Código Civil (CSJ/SPA, 1995).

Existe tanto en el derecho civil como en el derecho administrativo instituciones semejantes y constantes, estos son el daño y la relación de causalidad entre el daño y el hecho al cual se le atribuye la responsabilidad.

En lo referente a la relación de causalidad consiste en el vínculo que debe existir entre el hecho que origina la responsabilidad y el daño. Se establece que el vínculo se rompe cuando el daño es producto de la fuerza mayor, caso fortuito, hecho de un tercero o culpa de la víctima. En el campo de la responsabilidad de la Administración Pública, estas causas exoneratorias varían según el régimen de responsabilidad. Si se trata de responsabilidad por falta, el ente $u$ órgano de la Administración Pública se exonera por cualquiera de estas causas, por el contrario, en el campo de la responsabilidad sin falta y en las presunciones por funcionamiento anormal, operan solamente dos causas de exoneración: la fuerza mayor y la culpa de la víctima (Ortiz Alvarez, 1995).

Con la aparición de estas circunstancias exoneratorias se rompe total 0 parcialmente la relación de causalidad. En el caso Cedeño Salazar vs. CADAFE se demuestra la relación de causalidad "La relación de causalidad entre el hecho de la cosa y el daño causado es obvia, puesto que la electrocución no puede tener otra causa que no sea una descarga eléctrica, cualquiera que sea su frente 0 las circunstancias en que alcance el cuer- 
po de la víctima" (CSJ/SPA, 1985). Asimismo hace alusión la Corte que sólo con la demostración de alguna de las causales exoneratorias, la empresa demandada pudiera exonerarse:

Esta aseveración de la Corte resulta curiosa porque si había alguna causa exoneratoria que alegar era la fuerza mayor o la culpa de la víctima por tratarse de un caso de responsabilidad sin falta o por sacrificio particular (Ortiz Alvarez, 1995).

En el caso Alba Orsetti y Cabello Sánchez II la demandada pretende excepcionarse invocando la defensa de caso fortuito, sólo que la interposición de esta causal no procedió por considerarla la Corte extemporánea (CSJ/SPA, 1984).

En este mismo orden de ideas, a la jurisprudencia en el caso José Rafael Marín y Navol Bautista Martínez Díaz vs. CADAFE, se le objeta lo siguiente: En él se invocan sin necesidad las normas del Código Civil donde el actor pudo evadir ello y fundamentar su demanda, bajo el amparo de que los órganos de la jurisdicción contencioso-administrativa son competentes para condenar al pago de sumas de dinero y a la reparación de daños y perjuicios originados en responsabilidad de la administración y dentro de estos daños se incluirían tanto los materiales como los morales, sin hacer mención a los tipos de responsabilidad del Código Civil, lo cual se ha demostrado que es innecesario (CSJ/SPA, 1995).

Debe acotarse que en esta sentencia se está ante un caso de responsabilidad sin falta o por sacrificio particular donde probados los daños anormales y especiales y demostrada la relación de causalidad, la Administración Pública debe responder. Si esto es de esta manera ¿por qué entonces la Corte crítica el hecho de que la Administración Pública no se excepcionara demostrando alguno de los causales de exoneración, si no era necesario? Como se trataba de una responsabilidad sin falta solamente son admisibles como causales exoneratorias el hecho de la víctima y la fuerza mayor. Si la administración demostraba cualquiera de ellos dos se exoneraba, no debía demostrar todos los demás y mucho menos hacer mención al hecho del príncipe que nada tiene que ver como causal de exoneración en el campo de la responsabilidad de la Administración Pública.

\section{Normas de derecho administrativo relativas a la responsabilidad}

Existen normas legales dispersas, las cuales constituyen el soporte jurídico administrativo de la responsabilidad extracontractual de la Administración Pública. Estas normas forman parte del derecho administrativo interno y prescriben en su contenido la figura del daño como causa principal que da lugar a la indemnización en el sistema de responsabilidad de la Administración Pública.

\subsection{Normas adjetivas de derecho administrativo}

Constituyen en este caso los dos instrumentos normativos que regulan: en primer término, la vía administrativa representada por el procedimiento administrativo general: Ley Orgánica de Procedimientos Administrativos-, y en segundo 
término, la vía judicial o jurisdiccional contenciosa administrativa: Ley Orgánica de la Corte Suprema de Justicia?

En el primer instrumento jurídico se describe la relación jurídico procedimental, en la cual el órgano conocedor es la misma Administración Pública y el resultado está constituido por la figura del acto administrativo. En el segundo instrumento jurídico se establece la relación jurídico procesal, desplegada por los órganos jurisdiccionales para dirimir el conflicto de intereses entre dos partes, administración y administrado, el cual culminará con la producción de un acto judicial, denominado sentencia.

En el ámbito procedimental, la Ley Orgánica de Procedimientos Administrativos en materia de daño patrimonial contempla en el art. 6 lo siguiente: "Cuando la administración haya incurrido en mora o retardo en el cumplimiento de las obligaciones contraídas con los administrados y ello acarreare daño patrimonial, el funcionario o funcionarios a quienes competa la tramitación del asunto, además de las sanciones previstas en esta Ley, será responsable civilmente por el daño ocasionado a la administración" (Congreso Nacional, 1981).

De la disposición expuesta se infiere la institución de la responsabilidad directa del agente frente a la administración. Sólo es procedente en el régimen de responsabilidad por falta o funcionamiento anormal, la cual va a estar representado por la mora o retardo en el cumplimiento de las obligaciones contraídas que acarrean la producción de un daño patrimonial es la esfera subjetiva de los administrados.

En el ámbito procesal, la Ley Orgánica de la Corte Suprema de Justicia denota la producción de daños y perjuicios en el art. 131: "En su fallo definitivo la Corte declarará si procede o no la nulidad del acto impugnado y determinará los efectos de su decisión en el tiempo. Igualmente, la Corte podrá de acuerdo con los términos de la respectiva solicitud condenar el pago de sumas de dinero y a la reparación de daños y perjuicios originados en responsabilidad de la administración, así como disponer lo necesario para el restablecimiento de las situaciones jurídicas subjetivas lesionadas por la actividad administrativa" (Congreso Nacional, 1976).

Prescribe la anterior disposición el recurso de anulación y condena, en el cual no sólo se presenta un proceso cuya pretensión es la anulación del acto, sino que también se manifiestan como pretensiones, en primer lugar, la condena al pago de sumas de dinero y a la reparación de daños y perjuicios originados en responsabilidad de la administración, y en segundo lugar, disponer lo necesario para el restablecimiento de las situaciones jurídicas subjetivas lesionadas por la actividad administrativa. Por tanto, el recurso de anulación y condena no se trata de un proceso contra un acto administrativo, se trata de un proceso subjetivo en el cual existen demandante y demandado (En sentido contrario, vid. Brewer Carías, 1993:105).

2 Existen procedimientos administrativos y procesos administrativos especiales los cuales no son tratados en este estudio. 


\subsection{Normas de organización administrativa}

Estas normas legales se refieren a los daños y perjuicios producidos por la actividad ilícita de la Administración Pública, derivada de una actuación culpable de los agentes, la llamada Responsabilidad de los Funcionarios Públicos. La Ley, en este caso, objeto de estudio es el Decreto con fuerza y rango de Ley Orgánica de la Administración Central, considerada como una norma instrumental o de organización primaria, por la siguiente razón: crea órganos, les asigna atribuciones, competencias y responsabilidades ${ }^{3}$. $\mathrm{El}$ art. 11 prescribe "La República es responsable de los daños o perjuicios causados a los administrados por los actos $u$ omisiones de la Administración Central, a los que indemnizará bien en sede administrativa o una vez que tal responsabilidad sea declarada por los órganos judiciales competentes. Igualmente, pueden ser responsables civil, penal y administrativamente los funcionarios de la Administración Central que ordenen o dicten dichos actos de obligatorio cumplimiento, en cuyo caso la República puede repetir contra ellos las indemnizaciones canceladas a los administrados" (Presidente de la República, 1999).

De conformidad con esta disposición se presentan dos lineamientos a estudiar. En primer lugar, la determinación del ente responsable, constituido en el ámbito nacional por el ente político territo- rial representado por la República, responsable de los daños o perjuicios causados por todos los órganos que conforman la Administración Central,-- Presidente de la República, Vicepresidente Ejecutivo, Consejo de Ministros, Gabinetes sectoriales, Ministerios, Oficinas nacionales, Comisionados presidenciales, Servicios autónomos sin personalidad jurídica, Autoridades únicas de áreas o programas, Comisiones presidenciales o interministeriales, Procuraduría general de la República y Consejo de Estado -, los cuales podrán ser indemnizados en vía administrativa o en vía jurisdiccional, al interponer las acciones y recursos pertinentes. De igual forma existe Administración Central de carácter nacional y municipal, representados por el jefe del gobierno ejecutivo,- Gobernador- y el jefe del gobierno municipal- Alcalde, en cuyos casos, la determinación de los entes responsables estaría configurados por los entes políticos territoriales menores, el Estado y el Municipio, respectivamente.

En segundo lugar, se prescribe el fundamento legal de la acción de repetición, o también denominada acción de regreso: "la República puede repetir contra ellos las indemnizaciones canceladas a los administrados", la cual procede contra los agentes o funcionarios de la Administración Central, una vez que la República ha pagado directamente a los particulares los daños y perjuicios ocasionados y derivados de la actitud culpable de los funcionarios. En una primera fase los parde la Contraloría General de la República, Ley Orgánica de Régimen Municipal. 
ticulares, en virtud del principio de que la responsabilidad de la Administración Pública es directa, son indemnizados por la Administración Pública, pero ello no excluye la responsabilidad del funcionario 0 autoridad causante del daño. Los particulares agraviados pueden optar por exigir la responsabilidad directa de la Administración, y luego la misma podrá ejercer la acción de regreso contra aquellos funcionarios considerados culpables (Jiménez Lechuga, 1999).

Existe pues un parámetro legal de la acción de repetición, que debió de haber tenido origen constitucional, sin embargo el constituyente venezolano de 1999 no acogió esta figura.

\subsection{Normas de expropiación por causa de utilidad pública o social}

A la hora de definir la potestad expropiatoria, es menester emitir un concepto de expropiación pública, como mecanismo de derecho público y a su vez como institución de derecho público, en virtud de la cual la Administración Pública, procede coactivamente a la transferencia de la titularidad de la propiedad privada, como de bienes patrimoniales, en razón de la utilidad pública o interés social mediante justa indemnización, de conformidad con el procedimiento establecido en el ordenamiento jurídico positivo.

La potestad expropiatoria da lugar a esta relación jurídico administrativa, relación jurídica de derecho público, debido a que ésta surge como corolario del principio de supremacía de la administración, que permite a la Administración Pública actuar con potestad de imperio, e imponer a la colectividad el despojo patrimo- nial y como contrapartida de ello el particular recibe una justa y oportuna indemnización. La causa determinante de la potestad expropiatoria equivale en este caso a los fines. Únicamente con la finalidad de atender a la solución de problemas que interesen a la comunidad, a la construcción de obras que pueden ser de utilidad para el público, o de resolver cuestiones de interés social, está autorizada la Administración Pública para la expropiación de bienes. La exigencia de una utilidad pública sigue siendo imperiosa pero la legislación y la jurisprudencia han ampliado considerablemente el sentido dado a este concepto.

Ante todo, hay interés general naturalmente cuando la expropiación tiende a facilitar un funcionamiento de un servicio público; pero ella no se limita al servicio público, sino que se extiende a todo lo que tenga un carácter de utilidad general; en resumen se admite pura y simplemente la idea de utilidad pública expresada en el mismo título de la institución, sin restringirla, ciñéndola a conceptos técnicos, como el de dominio público, obra pública o servicio público (De Laubadere, 1984:293).

A la hora de estudiar las principales actuaciones legales de la Administración Pública que pueden ocasionar daños a los particulares se menciona la expropiación y como es sabido ella se refiere al derecho real por excelencia, la Propiedad.

La Carta Magna venezolana en el art. 115 establece: "Se garantiza el derecho de propiedad. Toda persona tiene derecho al uso, goce, disfrute y disposición de sus bienes. La propiedad estará sometida a las contribuciones, restricciones y obligaciones que establezca la ley con fines de utilidad pública o de interés gene- 
ral. Sólo por causa de utilidad pública o interés social, mediante sentencia firme y pago oportuno de justa indemnización, podrá ser declarada la expropiación de cualquier clase de bienes" (Asamblea Nacional Constituyente, 1999).

Como se expuso, la expropiación se relaciona, en primer lugar, con el derecho constitucional por contener la misma los planteamientos que en forma general esboza el Constituyente y que el Legislador ha seguido en la Ley de Expropiación por causa de Utilidad Pública o Social. En segundo lugar, la expropiación encuentra regulación en las normas del Código $\mathrm{Ci}$ vil, por ende la relación entre la expropiación y el derecho civil es marcada: por un lado, las disposiciones civiles que regulan la expropiación, entre ellas tenemos el art. 541 del CC: "Nadie puede ser obligado a ceder su propiedad, ni a permitir que otros hagan uso de ella, sino por causa de utilidad pública o social, mediante juicio contradictorio e indemnización previa. Las reglas relativas a la expropiación por causa de utilidad pública o social se determinan por leyes especiales" (Congreso Nacional, 1982).

En el otro aspecto que se relaciona la expropiación con el derecho civil son los bienes. El derecho civil específicamente en sus disposiciones sustantivas clasifica los bienes y nos delimita con especificidad lo que son bienes inmuebles, y lo que son bienes muebles. Esto nos da el sustento legal, la base legal cuando hablamos con propiedad y decimos qué clase de bien va a ser objeto de expropiación.

Ahora bien, la expropiación es una figura administrativa que por ende su regulación le compete al administrativista, al estudioso del derecho administrativo.
Se plantea en la práctica un procedimiento administrativo de expropiación, existen formalidades que deben ser cumplidas conjuntamente por la autoridad administrativa y las personas que fueren afectadas por la expropiación y las formalidades contenciosas (Polanco, 1959:135).

La expropiación en Venezuela está regulada en la "Ley de Expropiación por causa de utilidad pública o social" de fecha 4 de noviembre de 1947, reformada parcialmente por Decreto-Ley de la Junta de Gobierno, de fecha 25 de abril de 1958. En este instrumento normativo se encuentra consagrada la figura del daño patrimonial derivado de la potestad expropiatoria por causa de utilidad pública o social, en el art. 35, bajo el siguiente tenor: "Habrá lugar a indemnización cuando a los propietarios se los prive de una utilidad, queden gravados con una servidumbre o sufran un daño permanente que se derive de la pérdida o de la disminución de sus derechos" (Junta de Gobierno, 1958).

La jurisprudencia venezolana reseña el tratamiento de la expropiación en el caso C.A. Metro de Caracas al reiterar los criterios sustentados en los fallos del $12 / 10 / 91$ y 18/4/96. Así, se establece que la potestad expropiatoria debilita el derecho subjetivo de la propiedad al obtener coactivamente de los particulares aquellos bienes indispensables para la ejecución de las obras que demanda el interés público o colectivo. Su secuencia procedimental y procesal se encuentra configurada en las fases siguientes: A) Fase Inicial. La misma comprende la consignación de la solicitud ante el órgano jurisdiccional competente; solicitud de datos referidos al inmueble ante el Registrador 
Subalterno del lugar de la ubicación; emplazamiento de las personas que tengan o tuvieran algún interés sobre el bien; contestación de la solicitud; oposición y pruebas; relación; informes; sentencia y apelación. B) Fase Intermedia. Ella abarca el avenimiento y la fijación del valor de la cosa por las personas designados en el tribunal; y C) Fase Final. Con lo cual concluye el proceso al consignarse el monto de la indemnización determinado por el tribunal, y se materializa con el registro de la sentencia respectiva" (CSJ/SPA, 1998, citado por Pierre Tapia, 1998:227).

La expropiación se distingue en esencia de la responsabilidad de la Administración Pública. La expropiación es una actividad administrativa dirigida al despojo patrimonial de un bien perteneciente a un particular, que por razones de utilidad pú blica la administración lo necesita, por ello mediante sentencia firme y pago de justa indemnización se produce, es una activi dad dirigida a producirle un daño al particular, la Administración Pública lo indemniza. En el régimen de la responsabilidad de la Administración Pública, como consecuencia de su actividad se puede originar un daño, una lesión no procurada, por el funcionamiento anormal o normal de los servicios públicos, si esto sucede la administración debe indemnizar, pero ella no ha procurado el daño.

Garrido Falla (1992:260s.) cuando diferencia estas dos instituciones considera que cuando se produce el fenómeno de la expropiación la administración actúa lícitamente, sin culpa o negligencia. Además, el uso de la palabra indemnizado entraría en el campo de la expropiación mientras que en el sistema de responsabilidad se habla de particular lesio- nado. De esta manera el autor concluye que la actividad lícita de expropiar bienes se corresponde con la obligación por parte del administrado de soportar esta actividad justificada por el interés público, pero que origina una consecuencia como lo es el nacimiento del derecho a reclamar indemnización por parte del particular expropiado; mientras que la responsabilidad por actuaciones ilícitas que causan daño al particular justifica cabalmente el derecho de éste a exigir que la administración le repare el daño causado.

En este sentido la teoría de la indemnización expropiatoria y la teoría de la responsabilidad de la Administración Pública tienen basamentos constitucionales diferentes, pero que se complementan entre sí. Garrido Falla (1992:287) considera que ambas tienen un diferente punto de partida: la indemnización expropiatoria es la consecuencia de una actividad lícita de la administración con una simultánea consecuencia que se manifiesta en una compensación para el particular, como su derecho a percibir un justo precio por el bien perdido; en cambio la teoría de la responsabilidad, tiene su punto de partida en la idea de la falta del servicio y su finalidad es reparar el daño causado por su actuar o no actuar. En la expropiación, en cambio, sí existe un deber jurídico de soportar el despojo patrimonial mediante una justa indemnización (Cosculluela Montaner, 1997; Ortiz Alvarez, 1995).

En el caso Promociones Terra Cardón, se analizan los elementos diferenciadores de estas dos categorías indemnizatorias: “...en la expropiación la garantía de la indemnización, tiene su causa en el 'despojo patrimonial', por lo que tal indemnización es una carga tal que condi- 
ciona la procedencia misma de la expropiación. Por el contrario, la responsabilidad por la lesión causada por la actuación administrativa, descansa sobre el hecho de que, dada la posición del administrado, éste recibe una lesión no procurada" (CSJ/SPA, 1994a).

La expropiación genera responsabilidad de la Administración Pública por sus actuaciones legales que buscan la transferencia coactiva del derecho real de propiedad, mientras que en el sistema de responsabilidad de la Administración Pública propiamente dicho se genera un daño que es consecuencia de la actividad lícita o ilícita de la Administración Pública.

Finalmente, y con relación a otras normas de derecho administrativo se menciona la Ley Orgánica de Ordenación Urbanística prevé que la suspensión judicial de los efectos de los actos administrativos en materia de ordenación urbanística puede dar lugar a daños a terceros, los cuales deberán ser indemnizados, en el art. 94: "Cuando el propietario de la obra recurra a la vía jurisdiccional, el Juez o Tribunal que conozca de las acciones de nulidad de la orden administrativa de corrección, modificación, paralización o demolición, podrá suspender los efectos del acto mediante caución suficiente para garantizar el costo de la ejecución del acto y el de los daños y perjuicios a terceros" (Congreso Nacional, 1987).

La Ley Orgánica para la Ordenación del Territorio, en el art. 63, señala lo siguiente en materia de daños y perjuicios: "Los usos regulados y permitidos en los planes de ordenación del territorio, se consideran limitaciones legales a la propiedad y, en consecuencia, no originan, por sí solos, derechos a indemnizar. Esta sólo podrá ser reclamada por los propietarios en los casos de limitaciones que desnaturalicen las facultades del derecho de propiedad, siempre que produzcan un daño cierto, efectivo, individualizado, actual y cuantificable económicamente. En estos casos, a los efectos de determinar la indemnización, se seguirán los criterios establecidos en la Ley de Expropiación por causa de Utilidad Pública o Social" (Congreso Nacional, 1983).

En esta disposición se plantean los daños jurídicos y antijurídicos, también considerados normales y anormales. Con relación a los primeros, son considerados cargas comunes, los particulares están en la obligación de soportar ciertas limitaciones legales a la propiedad, por lo que no se consideran indemnizables, son daños que están obligados los particulares a soportar, mientras que en relación con la segunda categoría de daños, si estas limitaciones legales a la propiedad desnaturalizan el derecho real de propiedad, y producen un daño cierto y efectivo, (prueba de la realidad y la certeza de los daños cuyo resarcimiento se pretende), individualizado (con relación a una persona o grupo de personas), actual (no potencial o posible) y cuantificable económicamente, la indemnización procederá siguiendo los criterios establecidos en la Ley de expropiación por causa de utilidad pública o social.

La Ley de Tránsito Terrestre, en el art. 65, preceptúa: "La tramitación y las decisiones en los procedimientos administrativos, para establecer la responsabilidad administrativa originada por infracciones del tránsito, incluso cuando el accidente haya causado daños materiales a particulares, a la República, a los 
Estados o a los Municipios, es de la competencia de la autoridad administrativa del tránsito terrestre de la correspondiente circunscripción administrativa" (Congreso Nacional, 1996).

En esta disposición se plantea la responsabilidad por los daños materiales que pudieran derivarse de formas jurídicas de expresar la voluntad de la Administración Pública, representados en la producción de los actos de trámite y actos definitivos en vía administrativa, es decir, producidos en una relación jurídica de carácter procedimental.

\section{Conclusiones}

Este estudio contribuye a la consolidación de la siguiente teoría: Los principios normativos, de doctrina y de jurisprudencia de derecho público son aplicables a la institución de la responsabilidad de la Administración Pública de forma predominante, la institución de la responsabilidad civil del derecho privado juega un papel supletorio.

En materia de responsabilidad extracontractual de la Administración Pública, las normas del Código Civil sólo tendrán un valor determinante en el campo de la responsabilidad por funcionamiento anormal o por falta, cuando es relevante la conducta del funcionario que causó el daño y poder determinar qué tipo de falta ha cometido, es decir, si se trata de una actuación culposa, dolosa, ilegal.

En el campo de la responsabilidad sin falta la figura de la responsabilidad civil ordinaria no tiene ningún sentido y no goza de aplicación, acá no se estudia la conducta del funcionario, el estudio de la misma carece de relevancia, sólo es importante la producción del daño y que el mismo sea imputable a la Administración Pública.

Por otra parte, la figura del daño moral no afecta de ninguna manera la responsabilidad que se aplique, trátese de responsabilidad civil ordinaria o responsabilidad de la Administración Pública. Esta es una norma, cuya aplicación no desnaturaliza la esencia de la institución, muy por el contrario, la enriquece.

\section{Bibliografía citada}

Asamblea Nacional Constituyente (1999). CRBV. Gaceta Oficial de la República de Venezuela. No. 36860. 30/12/ 1999. Reimpresa por error material del ente emisor. Gaceta Oficial de la República Bolivariana de Venezuela. No. 5453 (Extraordinario). 24/3/ 2000. Caracas.

Brewer Carías, Allan (1993). Nuevas Tendencias en el Contencioso Administrativo en Venezuela. Editorial Jurídica Venezolana. Caracas.

Congreso Nacional (1961). CV. Gaceta Oficial de la República de Venezuela No. 662 (Extraordinario). 23/01/1961. Gaceta Oficial de la República de Venezuela No. 3357 (Extraordinario). 02/03/ 1984. Caracas.

Congreso Nacional. (1976). LOCSJ. Gaceta Oficial de la República de Venezuela. No. 1893 (Extraordinario). 30/06/ 1976. Caracas.

Congreso Nacional (1981). LOPA. Gaceta Oficial de la República de Venezuela. No. 2828 (Extraordinario). 1/07/1981. Caracas.

Congreso Nacional (1982). CC. Gaceta Oficial de la República de Venezuela. No. 2990 (Extraordinario). Julio 26. 
Congreso Nacional. (1983). LOOT. Gaceta Oficial de la República de Venezuela. No. 3238 (Extraordinario). 11/08/ 1983. Caracas.

Congreso Nacional (1987). LOOU. Gaceta Oficial de la República de Venezuela. No. 33868 (Extraordinario). 16/12/ 1987. Caracas.

Congreso Nacional (1996). LTT. Gaceta Oficial de la República de Venezuela. No. 5085 (Extraordinario). 9/8/1996. Caracas.

Cosculluela Montaner, Luis (1997). Manual de Derecho Administrativo. T. I. $8^{\circ}$ ed. Editorial Civitas. Madrid.

CSJ/SPA (1984). Sentencia del 19/07/1984. Caso Alba Orsetti -Cabello Sánchez II. Caracas.

CSJ/SPA (1985). Sentencia del 11/02/1985. Caso Cedeño Salazar - CADAFE. Caracas.

CSJ/SPA (1993). Sentencia del 7/10/1993. Caso Laboratorios Sanalo. Caracas.

CSJ/SPA (1994a). Sentencia del 27/01/1994. Caso Promociones Terra Cardón. Caracas.

CSJ/SPA (1994b). Sentencia del 24/3/1994. Caso Nemecio Cabeza-CADAFE. Caracas.

CSJ/SPA (1994C). Sentencia del 26/05/1994. Caso Asociación Educacional Ávila vs. República de Venezuela. Caracas.

CSJ/SPA (1994d). Sentencia del 30/11/1994. Caso Ramón Gallardo-INOS. Caracas.

CSJ/SPA (1994e). Sentencia del 7/12/1994. Caso Juan Simón Mijares CamejoINOS. Caracas.

CSJ/SPA (1995). Sentencia del 3/8/1995. Caso José Rafael Marín y Navol Bautista Martínez -CADAFE. Caracas.
De Laubadere, André (1984). Manual de Derecho Administrativo. (Trad. De Jesús Villamizar Herrera). Editorial TEMIS Librería. Bogotá. (Original francés, 1978).

Fundación Procuraduría General de la República (1983). Doctrina de la Procuraduría General de la República. Editorial Avila Arte. Caracas.

Fundación Procuraduría General de la República (1987). Doctrina de la Procuraduría General de la República. Editorial Avila Arte. Caracas.

Fundación Procuraduría General de la República (1993). Doctrina de la Procuraduría General de la República. Editorial Avila Arte. Caracas.

Garrido Falla, Fernando (1992). Tratado de Derecho Administrativo. T II. 10ma. ed. Editorial Tecnos. Madrid.

Jiménez Lechuga, Francisco (1999). La Responsabilidad Patrimonial de los Poderes Públicos en el Derecho Español: Una visión de conjunto. Marcial Pons, Ediciones Jurídicas y Sociales, S.A. Madrid Barcelona.

Junta de Gobierno (1958). LECUPS. Decreto Ley de la Junta de Gobierno. 25/04/1958. Caracas.

Ortiz Alvarez, Luis (1995). La Responsabilidad Patrimonial de la Administración Pública: Estudio del Derecho Venezolano y Análisis Comparativo con el Derecho Extranjero. Editorial Jurídica Venezolana. Caracas.

Pierre Tapia, Oscar (1989) (Comp). Jurisprudencia de la CSJ. Repertorio Mensual de Jurisprudencia No. 3. Editorial Jurídica Pierre Tapia. Caracas.

Pierre Tapia, Oscar (1991) (Comp). Jurisprudencia de la CSJ. Repertorio Mensual de Jurisprudencia No. 10. Editorial Jurídica Pierre Tapia. Caracas. 
Pierre Tapia, Oscar (1996) (Comp). Jurisprudencia de la CSJ. Repertorio Mensual de Jurisprudencia No. 8-9. Editorial Jurídica Pierre Tapia. Caracas.

Pierre Tapia, Oscar (1998) (Comp). Jurisprudencia de la CSJ. Repertorio Mensual de Jurisprudencia No. 2. Editorial Jurídica Pierre Tapia. Caracas.
Polanco, Tomás (1959). Derecho Administrativo Especial: Cursos de Derecho. Facultad de Derecho. Universidad Central de Venezuela. Caracas.

Presidente de la República (1999). DLOAC. Gaceta Oficial de la República de Venezuela. No. 36850. 14/12/1999. Caracas. 